\title{
Capacity-building needs assessment of rural health managers: The what and the how ...
}

\author{
C Goliath, ${ }^{1,2}$ M Occupational Therapy; F K Mukinda, ${ }^{1,2}$ MB ChB, MSc Clinical Epidemiology; L Dudley, ${ }^{1,2}$ MB ChB, MSc, FFPHM
}

${ }^{1}$ Centre for Health Systems and Services Research and Development, Stellenbosch University, Cape Town, South Africa

${ }^{2}$ Division of Community Health, Stellenbosch University, Cape Town, South Africa

Corresponding author: C Goliath (cdl@sun.ac.za)

Background. There has been a renewed focus on leadership and governance within the South African health workforce as a key to strengthening the health system. Several studies have highlighted that managers feel poorly prepared for their role and responsibilities and argue for support and development for healthcare managers. This study describes a 'training' need assessment conducted for health managers in a rural district which has informed Stellenbosch University Rural Medical Education Partnership Initiative (SURMEPI) continuing professional development activities. Objective. To determine the capacity-building needs and preferred approaches to capacity building for health managers in a rural district. Methods. The study used a mixed method design. A survey was conducted among healthcare managers followed by structured interviews with randomly selected participants. Results were discussed at a workshop and meetings with the district management, which allowed for triangulation and verification of results. Results. Thirty-two (68\%) of the 47 health managers in the district completed the questionnaires. Training needs for competencies related to: leadership; communication and knowledge management; infection prevention and control; community/public health and health systems research and strengthening were slightly higher than other areas. Facility managers were prioritised as a target group for leadership and management capacity development. The preferred learning approach was for more practice-based learning in the workplace, supported by e-learning rather than didactic classroom-based teaching.

Conclusion. Innovative approaches to capacity development and work-based support in developing intrinsic management competencies for front-line managers were highlighted in this needs assessment.

Afr J Health Professions Educ 2015;7(1 Suppl 1):92-97. DOI:10.7196/AJHPE.510

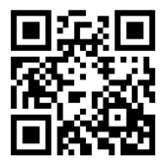

The World Health Organization (WHO) identified the human workforce as an important indicator of a well-functioning health system that is able to respond to the population's needs and to achieve the best outcomes possible given the available resources and circumstances. ${ }^{[1]}$ An effective workforce requires sufficient numbers and the right mix in terms of diversity and competencies to address healthcare needs. ${ }^{[1]}$

The role of health managers within the South African health workforce has been recognised as critical to strengthen the health system. ${ }^{[2]}$ This is reflected in national policy and plans, including the Human Resources for Health (HRH) strategy which identifies leadership, governance and accountability as one of eight priorities, and the National Department of Health's 10-Point Plan which highlights strategic leadership as a priority. ${ }^{[2,3]}$ These policies also prioritise the human resource gaps in rural areas, including the need to strengthen health managers' competencies.

Chen, quoted by Pillay, ${ }^{[4]}$ highlighted the lack of health managers' competencies as a constraint in achieving optimal health outcomes in South Africa (SA). Several studies have highlighted that health managers feel poorly prepared for their role and responsibilities and argue for further support and development for management competencies. ${ }^{[5,6]}$ Lockhart and Backman ${ }^{[7]}$ identify the biggest gaps in health management competencies in those who have to fulfil both clinical and management roles and often have the least management training. They argue that the greatest concern is that managers are placed in these positions without prior training and lack health management support programmes. Kippist and Fitzgerald ${ }^{[8]}$ highlight the conflict that exists in fulfilling the dual roles as they navigate between being managers and clinicians. Health managers of rural primary healthcare facilities in SA often fulfil the roles of both clinician and manager with the concomitant challenges, and thus require support in their dual role.

The health system is constantly changing and capacity-building programmes for health managers should enable them to adapt to and lead in rapidly evolving health systems. Pillay ${ }^{[4]}$ argues that any capacitydevelopment programme should be informed by a needs assessment. This is further supported by Wright et al., ${ }^{[9,10]}$ who identify competency needs assessment as a key component of any public health leadership programme.

Gilson and Daire ${ }^{[11]}$ argue for the strengthening of existing leadership and management programmes through more innovative approaches to support the large-scale reforms being implemented in the organisation and financing of the health system in SA. A study on capacity-building initiatives in three African countries (including SA) broadly classified initiatives in three categories, namely: academic qualifications, in-service training courses and on-the-job support and development. ${ }^{[12]}$ Formal training methods were the most common approaches in the three countries but work-based problemsolving and distance learning were also used. ${ }^{[12]}$ The study highlighted the importance of balancing time on training and workshops, and application of learned competencies on the job. It also emphasised the importance of developing programmes based on needs assessment, and not perceived needs, to improve managers' performance. ${ }^{[12]}$ 
The Stellenbosch University Rural Medical Educational Partnership Initiative (SURMEPI) aims to enhance competencies of health professionals to equip them to work in and strengthen health systems in rural and underserved areas. This includes the establishment of continuous professional development (CPD) activities for health professionals working in these areas. Identifying their training needs was an important task before the development of any capacity-building programme. This study describes a needs assessment conducted for health managers in a rural health district which has informed a SURMEPI capacity-building programme.

\section{Objective}

The aim of the study was to determine the capacity-building needs and preferred approaches to capacity building for health managers in a rural district.

\section{Methods}

The study, using a mixed method design, was conducted in one of the five rural health districts of the Western Cape, South Africa. The district is divided into four subdistricts and has a population of 238086 , of whom $83 \%$ are dependent on the public health sector. In 2011/2012 the health service platform consisted of 45 primary healthcare (PHC) facilities (23 non-fixed clinics, 21 fixed clinics, 1 community day centre) and 4 district hospitals. ${ }^{[13]}$

All 47 health managers on district, subdistrict and facility levels were invited to complete a self-administered questionnaire. The questionnaire had two components, focusing firstly on leadership and management competencies and secondly on health system strengthening competencies. The leadership and management component was adapted from previous surveys conducted in SA. The health systems competencies were based on core competencies for health professionals identified in SURMEPI for public health, health systems research, evidence-based healthcare and infection prevention and control (IPC) (Table 1). The questionnaire was piloted before being finalised.

Participants rated their need for capacity building and the importance of the leadership and management competencies in their work on a Likert scale

Table 1. Competencies included in the needs assessment questionnaires

\begin{tabular}{|c|c|}
\hline Leadership and management & Health system strengthening \\
\hline $\begin{array}{l}\text { - People management and creating } \\
\text { empowering environment } \\
\text { - Self-management } \\
\text { - Descision-making and initiating action } \\
\text { - Problem-solving and analysis } \\
\text { - Programme and project management } \\
\text { - Leadership } \\
\text { - Communication and knowledge } \\
\text { management } \\
\text { - Resource management and allocation } \\
\text { - Financial management } \\
\text { - Community/partnership } \\
\text { collaboration and customer } \\
\text { orientation }\end{array}$ & $\begin{array}{l}\text { - Public health } \\
\text { - Health system and services } \\
\text { research and strengening } \\
\text { - Evidence-based healthcare } \\
\text { - Infection prevention and control } \\
\text { - Clinical research }\end{array}$ \\
\hline
\end{tabular}

from 1 to $5(1=$ no importance and $5=$ very important $)$. A Likert scale from 1 to $4(1=$ no importance and $4=$ very important $)$ was used in the health system strengthening questionnaire to determine the need for capacity building in these competencies. Respondents also had to indicate their preferred approach, the timing and duration of capacity-building activities.

Seven participants were randomly selected for the semistructured interviews by level of management (district, subdistrict, programme and facility managers) to further explore priorities for capacity development and the best methods for delivering this for health managers in the district. The participants included two of the district management team members, a subdistrict manager, a PHC manager, two programme managers, and a facility manager. These interviews were conducted in the language of the participant and were recorded and transcribed.

Descriptive data from the questionnaires were captured and analysed using SPSS, a statistical software package, with the assistance of a statistician.

The qualitative data from the interviews were analysed through coding and category development. Themes were built from categories. ATLAS.ti, a qualitative analysis software program, was used to assist with organising and analysing the data.

All participants were invited to a workshop to discuss the results and identify priorities for the content and approaches for the capacitybuilding activities. This was followed by meetings with the four subdistrict management teams, as well as the district management team, to finalise content and approaches. This process allowed for triangulation and verification of results, as well as involvement of health managers in the interpretation and decision-making based on the results.

Ethical approval for the study was obtained from Stellenbosch University, Faculty of Medicine and Health Sciences, Health Research Ethics Committee: N10/12/067.

\section{Results}

Thirty-two (68\%) of the 47 health managers completed the questionnaires. One leadership and management questionnaire was incomplete. We analysed the 31 completed leadership and management questionnaires and 32 completed skills-development questionnaires.

The respondents were mainly females $(n=27 ; 87.1 \%)$, and more than $50 \%$ were older than 50 years old $(n=16 ; 51.5 \%)$. Most of the respondents $(n=22$; $67.7 \%$ ) had been in a management position for 5 or more years.

\section{Preferred content for a capacity-building programme}

Survey results from the leadership and management questions indicated little variation in the rating of importance of leadership and management competencies for their work. All the items were rated as important $(>4)$. Client orientation and customer satisfaction (mean 4.7; standard deviation (SD) 0.4 ) rated slightly higher than others. Similarly in their rating of need for support in training/development within the district, all items were rated as requiring training and support, with leadership, communication and knowledge management scoring highest (mean 3.7), and client and customer satisfaction the lowest (mean 2.8; SD 1.5)(Fig. 1).

Results from the health system strengthening questionnaire indicated that most of the participants viewed IPC $(n=26 ; 81.2 \%)$ as an important area within their work (Fig. 2).

The training needs were slightly higher in IPC (mean 3.1; SD 0.6) and community/public health and health system research and strengthening (mean 3.1; SD 0.6) than other areas (Fig. 3). 


\section{Research}

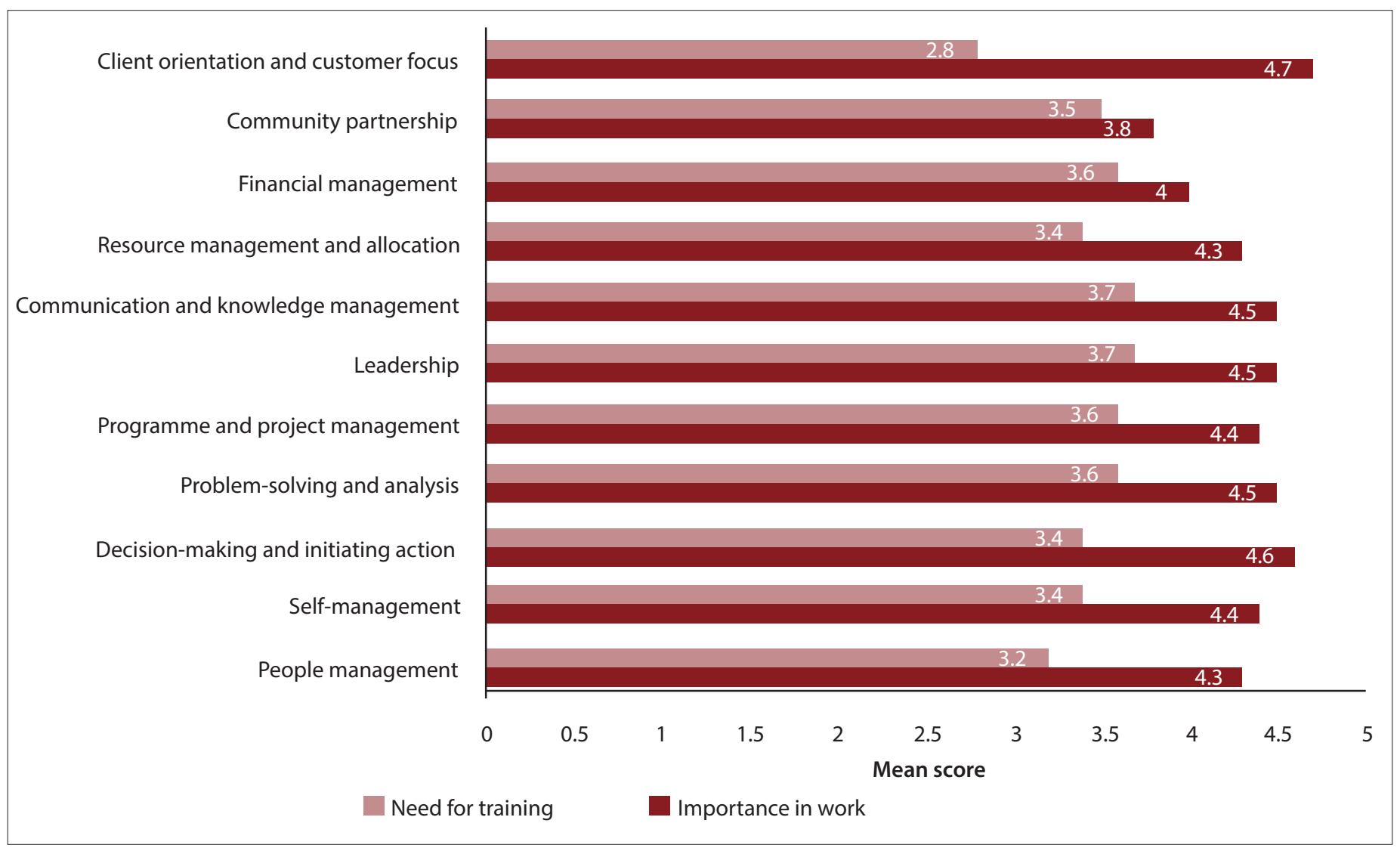

Fig. 1. Importance of and need for training in leadership and management competencies.

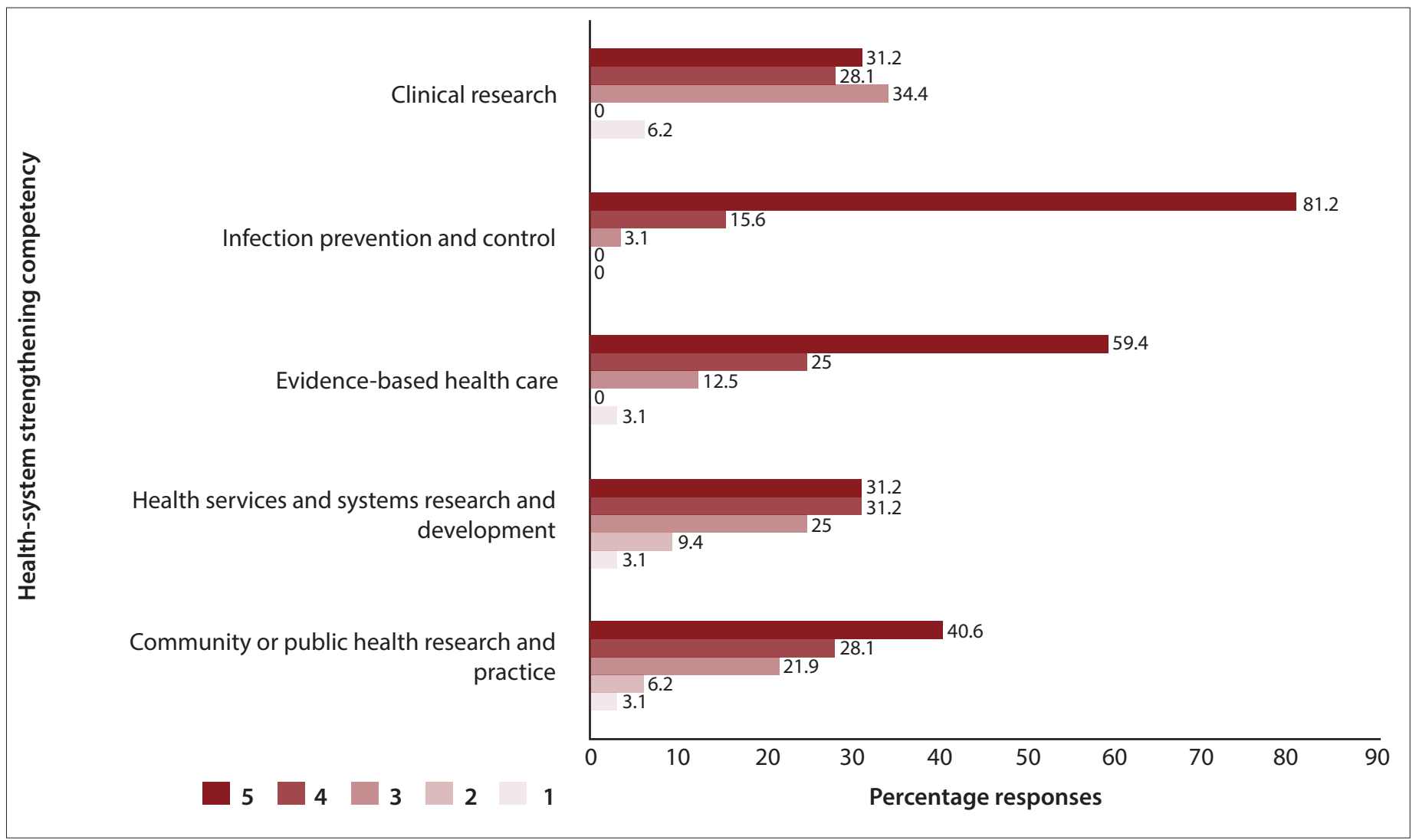

Fig. 2. Importance of health-system competencies for work. 
Although some areas were scored slightly higher than others, the mean scores were similar across all options, with overlapping SDs. These were therefore explored in greater depth in the semistructured interviews.

Three strong themes emerged from the interviews, viz. the lack of capacity-building activities related to intrinsic competencies in leadership and management, balancing roles, and strengthening management competencies to support the improvement in quality of care for the district. Managers indicated that they have access to capacity-building topics in aspects such as programme and project management. They lacked support in developing intrinsic competencies for people management and empowerment, selfmanagement, decision-making and initiating action; problem-solving and analysis; leadership; communication and knowledge management. They also experienced difficulty in applying these competencies in their daily management activities. As one manager stated, 'As managers we need to learn how to MANAGING UP (sic) and become MANAGERS OF MANAGERS?. (K1)

Finding the balance between manager and clinician emerged as an important theme for health managers. They reported struggling between the roles of clinician and manager. PHC facility managers in particular often have to fulfil both roles and found it difficult to balance their time and roles. The role of clinician takes preference over the role of manager, as staff shortages and patient waiting times have a strong influence on their choice of role. They also find it difficult to delegate work.

'Time management ... time management and delegating work, that is what we need support in.' (P5)

Quality improvement and healthcare evaluation were deemed as important to improve the quality of healthcare in the district, and were therefore prioritised for capacity building. IPC was confirmed as an important competency for facility staff. In addition, the interviewees highlighted the importance of IPC for community care workers and the lack of training and support on that level in the district.

\section{Preferred approach to capacity-building}

The preferred methods for capacity-building identified in the leadership and management questionnaire included coaching, mentoring, action learning networks and e-learning (Fig. 4). The numbers 3 - 5 in Fig. 4 represent the level of preference, with 3 being preferred and 5 being high preference.

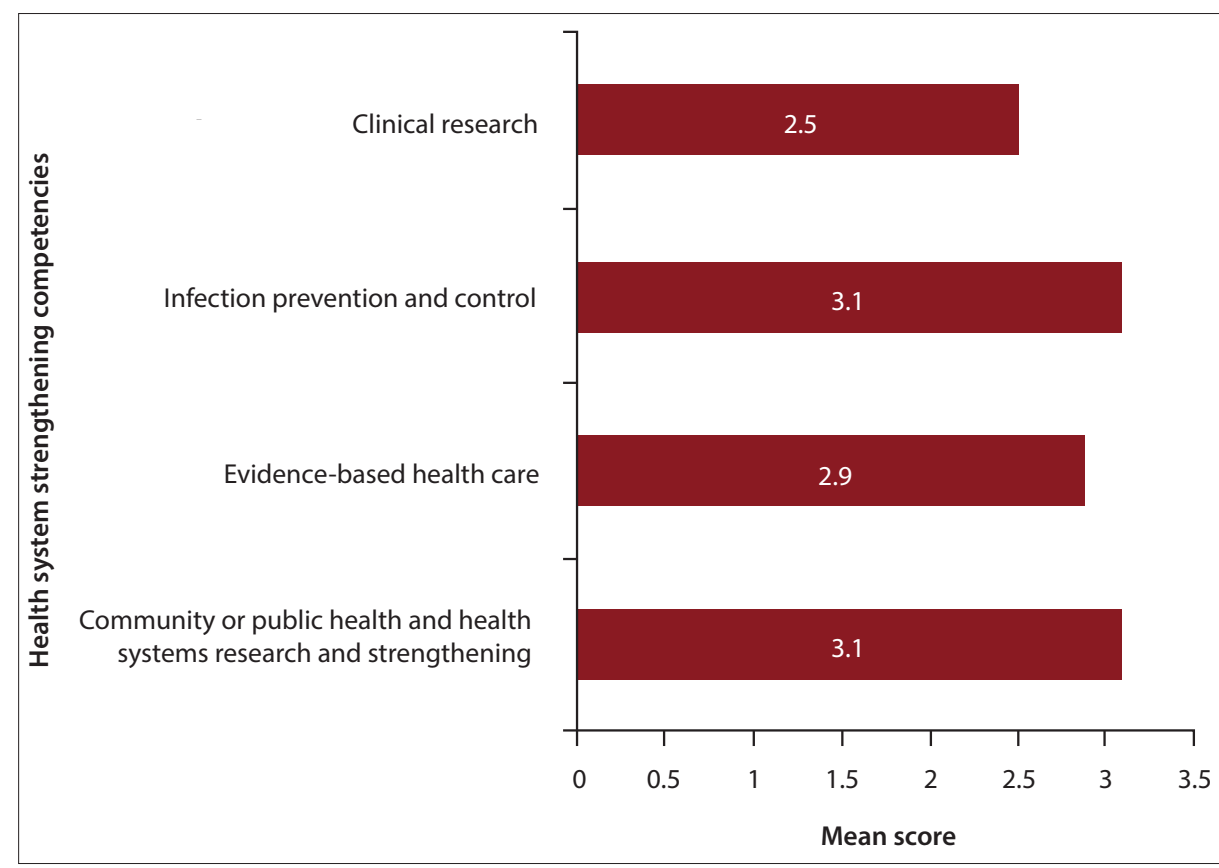

Fig. 3. Health system strengthening training needs.

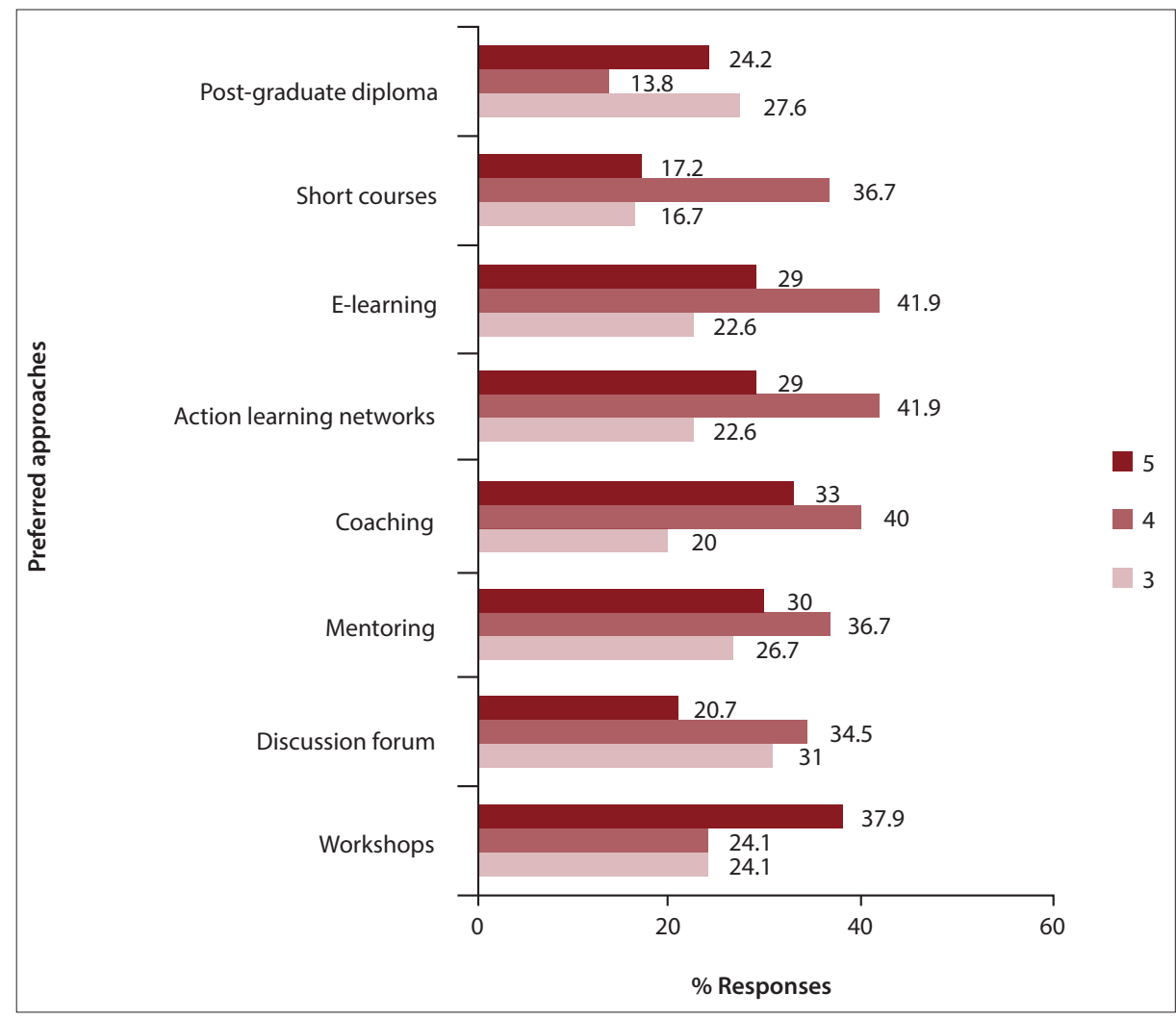

Fig. 4. Preferred approaches to building leadership and management capacities.

Results for the preferred method of health system strengthening capacity building indicated a preference for more active participation rather than a passive receiving of information, and a lower preference for formal training programmes and postgraduate courses (Fig. 5). The numbers
3 - 5 in Fig. 5 represent the level of preference, with 3 being preferred and 5 being high preference. The preferred approach to capacity building was for support in the application of learned knowledge. Managers expressed a need for a different approach to capacity building than the traditional approach of 


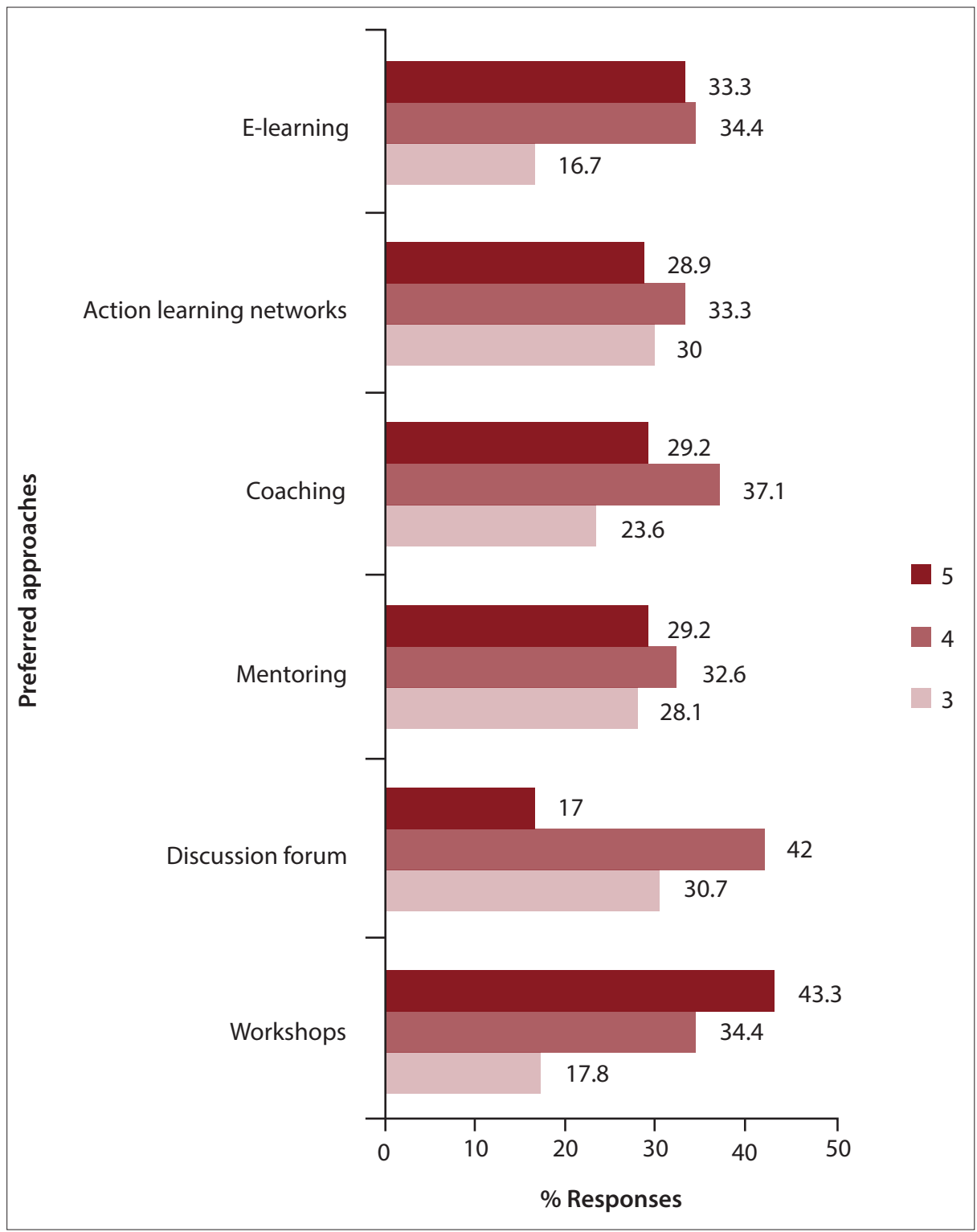

Fig. 5. Preferred approaches to building health system strengthening capacities.

formal training. Approaches of in-service training and work-based problem-solving were preferred.

'We get enough training. Help us to implement what we are being trained at.' (P2)

'This idea of training is great but it is one thing to sit in a workshop or class and listen and another to implement what is taught. We need support in implementing. Guide us and provide support in applying the knowledge.' (P3)

'We do not want more sitting and listening. Help us to make use of our management skills to improve the quality of care'. (P7)

'Do not take us out of our work. We do not have time to sit in a class. Find alternative ways of providing us with the knowledge but guide us in implementing. (P4)
The workshop was used to assist in the validation and interpretation of these results. It also provided input for recommendations on the content and approach to a health management development programme in the district. The results and recommendations were subsequently discussed with the district and subdistrict health management teams, where the target group, content and approach were refined as a health management development plan for the district.

During these discussions the PHC facility managers were prioritised as a key target group for leadership and management capacity development.

\section{Discussion}

The improvement of leadership and management competencies is a priority for the district and aligns with the Provincial and National Department of Health's strategies. Survey and interview results highlighted the need for support in the development and enhancement of intrinsic competencies of health managers.

Although the focus and priority for the district are in leadership and management, IPC and public health were highlighted as important in both the survey and interviews. This is aligned with the competing roles that the health managers fulfil, where the immediate demands of clinical care are often prioritised over their health management role and responsibilities.

Through the discussions with the district managers a proposed model of capacity building was defined which allowed for the integration of leadership and management competencies, with a particular focus on improving the quality of care which could be delivered in the workplace, and supported by e-learning resources.

The prioritisation of managers of PHC facilities in this study confirms findings of others and the argument for more support given the complexity of their multiple roles and lack of readiness for their role as manager and leader. ${ }^{[2,4,5]}$

The participants did not want further 'training' to acquire knowledge, but expressed a preference to be supported in implementing practices in their work through mentoring and coaching. The result is in contrast to findings of Gould et al. ${ }^{[5]}$ where the preferred CPD method was part-time courses and study days. This challenges traditional methods of providing CPD and highlights the need for innovation that combines traditional and alternative approaches. ${ }^{[10]}$ The study also challenges the traditional design of capacity building where the focus is on trainers determining the curriculum, educational objectives and assessment $v$. the move towards competency-based education, where the focus is on the needs of the health system, and development of competency outcomes based on these needs is what informs the curriculum design.

The study further highlights the importance of context in the development of capacity building and CPD activities. With an ageing cohort of managers, succession planning as part of capacity building is important in the district. Managers will need to be supported to develop their own competencies further, and to develop the competencies in younger team members to ensure management succession within the district. 
The study was limited to one rural district in the Western Cape, and may therefore not represent training needs or preferred methods of capacity development in other areas. The questionnaires were distributed and collected by the human resource development manager and therefore the researchers did not have control over the actual number of questionnaires distributed.

\section{Conclusion}

Innovative approaches and the inclusion of intrinsic competencies as an important aspect of capacity development and work-based support in developing leadership and management competencies for front-line managers were highlighted in this needs assessment. The findings have informed SURMEPI CPD activities and the district training plan, which focus on strengthening the leadership and management competencies of operational managers while also improving the quality of care and health outcomes at their facilities.

Authors' contributions. All authors made substantial contributions to the conception, design, data acquisition and analysis, and interpretation of the quantitative and qualitative results. All authors critically revised the draft for intellectual content, and approved the final version of the manuscript prior to submission.

Acknowledgements. Funding from the US President's Emergency Plan for AIDS Relief (PEPFAR) through Health Resources and Services Administration
(HRSA) under the terms of T84HA21652 via the Stellenbosch University Rural Medical Education Partnership Initiative (SURMEPI) is gratefully acknowledged. The researchers further acknowledge the contributions made by the District Management Team of the Overberg Health District, and the SURMEPI Focus Area 2 team including T Young, A Dramowski, B Willems and T Esterhuizen.

\section{References}

World Health Organization. Key Components of a Well-functioning Health System. Geneva: World Health Organization, 2010. http://www.who.int/healthsystems/publications (accessed 16 October 2012)

2. National Department of Health. National Strategic Plan 2010/2011 - 2012/2013. Pretoria: NDoH, 2010. http:// www.nationalplanningcycles.org/sites/default/files/country_docs/South\%20Africa/south_africa_strategic health_plan_2010-2013.pdf (accessed 5 November 2012).

3. National Department of Health. Human Resources for Health South Africa: HRH Strategy for the Health Sector: 2012/2013 - 2016/2017. Pretoria: NDoH, 2011. http://www.gov.za/documents/download (accessed 15 June 2013). 4. Pillay R. The skills gap in nursing management in South Africa: A sectoral analysis: A research paper. Journal of Nursing Management 2010,18:134-144. [http://dx.doi.org/10.1111/j.1365-2834.2010.01063.x]

Nursing Management 2010,18:134-144. [http://dx.doi.org/10.1111/j.1365-2834.2010.01063.x] 5. Gould D, Kelly D, Goldstone L, et al. The changing training needs of clinical nurse managers: Exploring issues for con
professional development. J Adv Nurs 2001;34(1):7-17. [http://dx.doi.org/10.1046/j.1365-2648.2001.3411735.x]

professional development. J Adv Nurs 2001;34(1):7-17. [http://dx.doi.org/10.1046/j.1365-2648.2001.3411735.x]
6. Spehar I, Frich JC, Kjekshus LE. Clinician's experience of becoming a clinical manager: A qualitative study. BMC Spehar I, Frich JC, Kjekshus LE. Clinician's experience of becoming a clinical manager: A qua
Health Services Research 2012;12(421):1-11. [http://dx.doi.org/10.1186/1472-6963-12-421]

7. Lockhart W, Backman A. Health care management competencies: Identifying the gaps. Health Care Management Forum 2009;22(2):30-37. [http://dx.doi.org/ 10.1016/S0840-4704(10)60463-2]

8. Kippist L, Fitzgerald A. Organisation professional conflict and hybrid clinician managers: The effect of dual roles in Australian health care organisations. Journal of Health Organisation and Management 2009;23(6):643-655 [http://dx.doi.org/10.1108/14777260911001653]

9. Wright K, Rowitz L, Merkle A, Reid W, Robinson G, Herzog B. Competency development in public health leadership. Am J Public Health 2000;90:1202-1207. [http://dx.doi.org/10.2105/AJPH.90.8.1202]

10. Wright K, Rowitz L, Merkle A. A conceptual model for leadership development. J Public Health Manag Pract 2001;3(5):72-79.

11. Gilson L, Daire J. Leadership and Governance in the South African Health System. In: Health Systems Trust. South African Health Review 2011. Durban: Health Systems Trust, 2011. http://www.hst.org.za/sites/default/ files/sahr_2011.pdf (accessed 13 March 2014).

12. World Health Organization. Managing the Health Millennium Development Goals - The Challenge of Management Strengthening: Lessons from Three Countries: Working Paper No. 8, 2007. http://www.who.int/ management/working_paper_8_en_opt.pdf (accessed 29 July 2014).

13. Western Cape Department of Health: Overberg District. District Health Plan 2013/2014. http://www. westerncape.gov.za/.../departments/health/annual_report_2012-13 (accessed 29 July 2014). 